\title{
The Noble Values of the Samin Community
}

\author{
Nur Wahyu Rochmadi \\ Program Studi PPKn, FIS, Universitas Negeri Malang \\ nur.wahyu.fis@um.ac.id
}

\section{Article History}

accepted 23/03/2021

approved 10/04/2021

published 20/04/2021

\begin{abstract}
The Samin community was phenomenal, because the actualization of their noble values was able to make the Dutch colonialists inconvenient, even when the Indonesian nation became independent, and the Indonesian state was established until now. The purpose of this research is to explore the noble values of the Samin people, then they are used as role models in developing the character of citizens. The research was conducted with a descriptive qualitative design. The research subjects were traditional elders, community leaders, families and other parties who had interacted with the Samin community. Data collection was carried out through observation, interviews and documentation. Data were analyzed by referring to an interactive model. The research findings explain that the noble values of the Samin community include: (a) honesty; (b) simple / prasojo; (c) extension; (d) mutual cooperation; (e) rilo, selfless, sincere; (f) friends; diligent, tenacious and painstaking; (g) ora drengki, srei, dahpen kemiren; (h) independence; and (i) fair. Based on these findings, it is suggested (1) the noble values of the Samin community be used as a reference in developing the character of citizens; and (2) character education practice must be preceded by determining the main values.
\end{abstract}

Keywords: value, character, Samin

\begin{abstract}
Abstrak
Masyarakat Samin adalah fenomenal, karena aktualisasi nilai-nilai luhur yang dilakukannya mampu menjadikan penjajah Belanda kerepotan, bahkan ketika bangsa Indonesia merdeka, dan negara Indonesia berdiri hingga sekarang. Tujuan dari penelitian ini adalah mengeksplorasi nilai-nilai luhur masyarakat Samin, selanjutnya dijadikan panutan dalam pengembangan karakter warganegara. Penelitian dilaksanakan dengan rancangan kualitatif deskriptif. Subjek penelitian adalah tetua adat, tokoh masyarakat, keluarga serta pihak-pihak lain yang pernah berinteraksi dengan masyarakat Samin. Pengumpulan data dilakukan melalui pengamatan, wawancara dan dokumentasi. Data dianalisis dengan mengacu pada model interaktif. Temuan penelitian menjelaskan bahwa nilai-nilai luhur masyarakat Samin antara lain: (a) jujur; (b) sederhana/prasojo; (c) paseduluran; (d) gotong royong; (e) rilo, tanpa pamrih, ikhlas; (f) temen; rajin, ulet dan telaten; (g) ora drengki, srei, dahpen kemiren; (h) kemandirian; dan (i) adil. Berdasarkan temuan tersebut disasarankan (1) nilai-nilai luhur masyarakat Samin dijadikan acuan dalam pengembangan karakter warganegara; dan (2) praktek pendidikan karakter harus diawali dengan penentuan nilai utama.
\end{abstract}

Kata Kunci: nilai, karakter, Samin

Social, Humanities, and Education Studies (SHEs): Conference Series https://jurnal.uns.ac.id/shes

p-ISSN 2620-9284 e-ISSN 2620-9292 


\section{PENDAHULUAN}

Tujuan pendidikan di Indonesia untuk mencerdaskan kehidupan bangsa, yang arahnya pada pengembangan keterampilan dan ilmu pengetahuan, sebagai penyalur dan pengembang karakter luhur bangsa, serta pembangun tumbuhnya rasa kebangsaan warganegara (BSNP, 2010). Pada dasarnya tujuan Pendidikan di setiap negara adalah untuk meningkatkan dan mengembangkan pengetahuan dan keterampilan warga negara, menjadikan warga negara yang baik serta mengembangkan karakter luhur warga negara sesuai dengan nilai-nilai budaya bangsa. Demikian halnya dengan sistem pendidikan

Permasalahannya, praktek pendidikan selama ini lebih banyak terfokus pada pengembangan pengetahuan dan keterampilan, dibandingkan dengan pengembangan karakter luhur warga negara. Selama ini pendidikan di Indonesia terlalu menekankan aspek intelektualitas, kurang memperhatikan aspek moralitas dan sikap, lebih banyak berkaitan dengan penyediaan sumberdaya manusia untuk pemenuhan kepentingan pasar dan industri, ketimbang pengembangan karakter dan kearifan warganegara.

Perhatian pada aspek pengembangan karakter luhur bangsa, serta membangun tumbuhnya rasa kebangsaan warganegara dalam sistem pendidikan di Indonesia terasa lebih aktif, intensif dan terencana ketika diberlakukannya kurikulum 2013 hingga sekarang.

Praktek pengembangan karakter luhur warga negara di Indonesia selama ini diwadahi dalam mata pelajaran pendidikan Pancasila dan Kewarganegaraan (PPKn). Mata pelajaran pendidikan Pancasila dan Kewarganegaraan (PPKn) merupakan mata pelajaran yang memfokuskan pada pembentukan warga negara yang baik, yang memiliki perilaku dan moral sesuai dengan nilai-nilai Pancasila, serta memahami dan mampu melaksanakan hak-hak dan kewajibannya untuk menjadi warga negara Indonesia yang cerdas, terampil, dan berkarakter sebagaimana yang diamanatkan oleh Pancasila dan UUD negara Republik Indonesia tahun 1945.

Pendidikan Pancasila dan Kewarganegaraan (PPKn) di negara lain dikenal sebagai civic education dalam konteks wacana pendidikan untuk kewarganegaraan menurut konstitusi dan ideologi negaranya masing-masing (Winataputra: 2005). Sebagai Pendidikan kewarganegaraan, PPKn merupakan wahana pendidikan karakter (character education) yang oleh Cogan and Derricott mata pelajaran tersebut bersifat multidimensional (Cogan and Derricott: 1998).

Permasalahanya tujuan nata pelajaran PPKn terkesan kontradiktif antara yang dialami oleh peserta didik di lingkungan luar sekolah dengan yang diterima di sekolah. Materi pelajaran PPKn tidak selaras (kedap) dengan kondisi riil yang terjadi di lingkungan sekitar, sehingga apa yang disampaikan guru menjadi kurang bermakna bagi kehidupan peserta didik. Terdapat jarak, antara materi di kelas dengan kondisi realitas yang dialami peserta didik, terutama materi yang berkaitan dengan pendidikan moral, pendidikan karakter untuk warga negara.

Karakteristik dan permasalahan dalam pembelajaran pendidikan Pancasila dan Kewarganegaraan sebagai pendidikan karakter dan kewarganegaraan tersebut di atas menuntut ditemukannya suatu bahan ajar yang mampu mewujudkan tujuan pembelajaran yang bersifat pengetahuan, sikap dan keterampilan kewarganegaraan secara integratif serta kemampuan dalam pemecahan masalah kewarganegaraan sebagaimana tertera dalam tujuan Pendidikan Pancasila dan Kewarganegaraan (Permendiknas No 68/2014), yaitu perwujudan civic virtues (kemuliaan kewarganegaraan) melalui pengembangan secara interaktif dan sinergis kemampuan: civic knowledge, civic dispositions, civic skills, civic confidence, civic committment, civic competence, yang bermuara pada perwujudan civic responsibility dan civic enggagement.

Paparan di atas menegaskan pentingnya untuk mengembangkan materi pembelajaran serta model pembelajaran pendidikan Pancasila dan kewarganegaraan 
yang inovatif sebagai wahana pengembangan karakter warga negara serta sebagai pendidikan kewarganegaraan, agar dapat mengembangkan kecerdasan warga negara (civic intelligence), tanggung jawab warga negara (civic responsibility), serta mengembangkan partisipasi warga negara (civic participation) sehingga terwujud civic responsibility, civic engagement, dan civic virtue.

Masyarakat Indonesia dikenal memiliki kekayaan budaya nilai-nilai luhur yang diakui kebenarannya, diaktualisasikan dan diwariskan antar generasi hingga sekarang oleh kelompok-kelompok budaya tradisional. Nilai-nilai luhur tersebut ada pada setiap kelompok masyarakat Indonesia, dan menjadi kepribadian bangsa Indonesia.

Nilai-nilai luhur bangsa Indonesia tersebut diaktualisasikan dalam kehidupan sehari-hari, ditransformasi dan diinternalisasikan pada generasi berikutnya dengan menggunakan berbagai macam pola. Namun yang jelas, proses aktualisasi dan internalisasinya mengalami keberhasilan, terbukti dengan adanya kelestarian dari nilainilai luhur budaya bangsa tersebut dalam kehidupan sehari-hari bangsa Indonesia hingga sekarang. Walau tidak menutup mata adanya keberagaman hasil atas aktualisasi dan proses internalisasi tersebut, sebagai akibat dari adanya perkembangan masyarakat serta ilmu pengetahuan dan teknologi, namun demikian diakui bahwa ada keberhasilan dalam melestarikan nilai-nilai luhur tersebut secara konsisten. Salah satu dari kelompok masyarakat tersebut adalah masyarakat Samin di Bojonegoro.

Berdasarkan latar belakang tersebut dilakukanlah kegiatan eksplorasi tentang nilai-nilai luhur pada masyarakat Samin, dengan tujuan untuk mendeskripsikan nilainilai luhur yang dimiliki masyarakat Samin hingga kini, yang selanjutnya dijadikan acuan dalam kegiatan pengembangan karakter warganegara Indonesia.

\section{METODE}

Penelitian ini dilaksanakan dengan dengan tujuan melakukan studi eksplorasi terhadap nilai-nilai luhur pada masyarakat Samin di Bojonegoro, Jawa Timur. Berdasarkan tujuan tersebut, penelitian ini dilaksanakan dengan rancangan kualitatif deskriptif. Subjek penelitian ini adalah Harjo Kardi (sesepuh); Novi (Ibu rumah tangga); Bambang, anak sesepuh; Yuni; Dewi, Januani; dan Joko, Pemilik, pedagang toko.

Pengumpulan data dilaksanakan dengan melakukkan wawancara kepada informan, melakukan observasi lingkungan, dan dokumentasi. Analisis data dilakukan melalui kegiatan brainstorming dan focus group discussion. Data dianalisis mengacu pada model interaktif dari Miles dan Hubermans.

\section{Nilai-nilai Luhur Masyarakat Samin}

\section{HASIL DAN PEMBAHASAN}

Samin adalah sebuah fenomena tentang bentuk perjuangan masyarakat melawan penjajah Belanda yang dimotori oleh seorang yang bernama Samin Surosentiko. Samin Surosentiko mengajarkan, melakukan dan mengobarkan semangat perlawanan terhadap penjajah dalam bentuk tanpa kekerasan. Mereka melakukan perlawanan dengan cara menolak membayar pajak, menolak segala peraturan yang dibuat pemerintah kolonial, menolak terhadap budaya kolonial Belanda, serta menolak terhadap kapitalisme.

Perlawanan terhadap penjajah dilakukan tidak secara fisik tetapi berwujud melakukan hal yang bertentangan dengan ketentuan yang ada dalam segala peraturan dan kewajiban yang harus dilakukan rakyat terhadap penjajah misalnya ada perintah menanam padi, masyarakat Samin menanam jagung, ada perintah untuk sekolah, masyarakat Samin mengajak anaknya ke swah, dan sebagainya. Perlawanan ini diikuti oleh banyak penduduk di wilayah tersebut, dan menjadikan gangguan yang sangat merepotkan bagi penjajah Belanda dan Jepang, demikian halnya saat awal Indonesia merdeka. 
Sikap masyarakat Samin yang menentang pemerintahan penjajah dengan cara seperti tersebut, menjadikan mereka membuat tatanan, adat istiadat dan kebiasaankebiasaan tersendiri di lingkungan tempat tinggalnya (Harjo Kardi, desa Jipang, Margomulyo, Bojonegoro, 17 Juli 2018). Tatanan kehidupan yang dikembangkan oleh Samin Surosentiko ini, menjadikan kelompok masyarakat tersebut memiliki identitas, karakter, yang membedakan dengan masyarakat lainnya.

Tatanan kehidupan manusia dan masyarakat yang dikembangkan oleh Samin Surosentiko mengacu kepada nilai-nilai kebenaran, kesederhanaan, kebersamaan, keadilan, dan kerja keras (Harjo Kardi, 2018, desa Jipang, Margomulyo, Bojonegoro, 17 Juli 2018). Selanjutnya nilai-nilai tersebut dijadikan pedoman dalam kehidupan sehari-hari, disebut dengan istilah "angger-angger". Menurut Harjo Kardi (desa Jipang, Margomulyo, Bojonegoro, 17 Juli 20182018) "ada tiga angger-angger dalam kehidupan masyarakat Samin, yaitu: (1) angger-angger pangucap (hukum bicara); (2) anggerangger pratikel (hukum tindak tanduk); dan (3) angger-angger lakonono (hukum perihal yang perlu dijalankan, kewajiban)".

Masyarakat Samin memiliki "kitab suci". Kitab suci itu adalah Serat Jamus Kalimasada yang terdiri atas Serat Punjer Kawitan, Serat Pikukuh Kasajaten, Serat UriUri Pambudi, dan Serat Lampahing Urip. Berpedoman pada kitab tersebut, masyarakat Samin hendak membangun sebuah negara batin yang jauh dari sikap drengki srei, tukar padu, dahpen kemeren Eyang Harjo Kardi (desa Jipang, Margomulyo, Bojonegoro, 17 Juli 20182018).

Menurut Ibu Januani (SMPN 4 Blora, 19 Juli 2018), "masyarakat samin lebih suka disebut wong sikep yang maknanya orang yang bertanggung jawab suatu sebutan untuk orang yang berkonotasi baik, jujur. Dalam masyarakat samin mereka mengenal istilah "Wong sikep kukoh wali Adam, wong sikep kukoh nabi Adam" (Wong sikep sangat kuat pertalian laki laki dan perempuan)".

Bilamana dibandingkan dengan pernyataan yang disampaikan oleh sesepuh masyarakat Samin saat ini (Hardjo Kardi, desa Jipang, Margomulyo, Bojonegoro, 17 Juli 2018) yang menyatakan bahwa: "wong Samin meniko opo anane, jujur, prasojo, paseduluran, gotong royong, rilo, tanpa pamrih, ikhlas, temen, rajin, ulet, telaten, gemi, satiti, ngati-ati, mandiri, dan adil",

Berdasarkan wawancara dengan beberapa pihak tentang nilai-nilai luhur yang dimiliki masyarakat Samin sehingga menjadi identitas dari mereka secara turun temurun, dapat disimpulkan sebagai berikut: (1) jujur; (2) sederhana/prasojo; (3) paseduluran; (4) gotong royong; (5) rilo, tanpa pamrih; ikhlas; (6) temen; rajin, ulet dan telaten; (7) gemi, satiti, dan ngati-ati; (8) apa adanya; (9) kemandirian; dan (10) adil.

Proses aktualisasi nilai-nilai luhur bangsa dan pengembangan karakter warganegara menghendaki adanya suatu proses yang berkelanjutan, dilakukan dalam beragam ranah serta melalui berbagai kegiatan.

Dalam mengembangkan pendidikan karakter bangsa, kesadaran akan siapa dirinya dan bangsanya adalah bagian yang teramat penting. Kesadaran tersebut hanya dapat terbangun dengan baik melalui sejarah yang memberikan pencerahan dan penjelasan mengenai siapa diri bangsanya di masa lalu yang menghasilkan dirinya dan bangsanya di masa kini.

Selain itu, pendidikan harus membangun pula kesadaran, pengetahuan, wawasan, dan nilai berkenaan dengan lingkungan tempat diri dan bangsanya hidup (geografi), nilai yang hidup di masyarakat (antropologi), sistem sosial yang berlaku dan sedang berkembang (sosiologi), sistem ketatanegaraan, pemerintahan, dan politik (ketatanegaraan/politik/kewarganegaraan), bahasa Indonesia dengan cara berpikirnya, kehidupan perekonomian, ilmu, teknologi, dan seni. Artinya, perlu ada upaya terobosan kurikulum berupa pengembangan nilai-nilai yang menjadi dasar bagi pendidikan budaya dan karakter bangsa. 
Dengan demikian, nilai dan karakter yang dikembangkan pada diri peserta didik akan sangat kokoh dan memiliki dampak nyata dalam kehidupan diri, masyarakat, bangsa, dan bahkan umat manusia. Pernyataan selaras dengan praktek kehidupan nyata yang berlangsung pada masyarakat Samin, sebagaimana temuan penelitian di atas.

Kajian tentang tujuan dalam pendidikan karakter pada dasarnya adalah dalam rangka untuk memperbaiki kemerosotan moral manusia. Menurut Foerster (Koesoema, 2010:42) tujuan pendidikan karakter adalah untuk membentuk perilaku seseorang secara utuh, karakter merupakan sesuatu kualifikasi pribadi seseorang sebagai kesatuan dan kekuatan atas keputusan yang diambilnya.

Sedangkan menurut Arthur (2003:11 dalam BSNP. 2010) pendidikan karakter bertujuan untuk memperbaiki pribadi individu, seperti yang telah dikemukakannya, yaitu: the aim of the institute was to improve the habits, dispositions and general character of the chlidren. Jadi, pendidikan karakter bertujuan untuk memperbaiki kebiasaan, watak, dan karakter pada anak.

Menurut Samani dan Hariyanto (2012:43) pendidikan karakter bertujuan membina perilaku peserta didik yang baik sehingga berguna bagi tiap orang. Artinya pendidikan karakter bukan sekedar memahami aturan benar salah atau mengetahui tentang ketentuan baik buruk, tetapi harus benar-benar terwujud dalam perilaku moral yang baik pada diri dan mengimplementasikan kepada masyarakat.

Tujuan pendidikan karakter yang dikemukakan oleh beberapa pihak di atas, tidak jauh berbeda dengan praktek yang terjadi pada masyarakat Samin, yang intinya adalah agar kehidupan dan peradaban manusia menjadi lebih baik, artinya sesuai dengan nilai-nilai luhur yang menjadi acuan dalam kehidupannya,

Pendidikan karakter mempunyai peran penting dalam pengembangan sumber daya manusia melalui pendidikan. Oleh karena itu, perlu adanya fokus perhatian terhadap jenis-jenis watak dan nilai-nilai tertentu untuk dikembangkan sehingga menjadi bagian perilaku peserta didik.

Fokus perhatian pengembangan karakter bangsa Indonesia terletak pada enam nilai, yakni tiga berdimensi personal (jujur, akal sehat, dan pemberani), dan tiga lainnya berdimensi sosial (adil, tanggung-jawab, dan toleran). Bila pengembangan keenam nilai ini benar-benar dikembangkan secara professional dan dalam lingkup nasional, tak mustahil peningkatan kualitas manusia Indonesia dalam kurun waktu satu generasi saja akan terjadi (BSNP, 2010).

Selain itu, juga perlu dikembangkan sembilan sikap luhur yang ditanamkan sejak dini pada anak-anak Indonesia di sekolah. Sikap itu adalah: (1) cinta Tuhan dan kebenaran, (2) tanggung-jawab, kedisiplinan dan kemandirian, (3) amanah, (4) hormat dan santun, (5) kasih sayang, kepedulian, dan kerjasama, (6) percaya diri, kreatif, dan pantang menyerah, (7) keadilan dan kepemimpinan, (8) baik dan rendah hati, dan (9) toleransi dan cinta damai. Kemudian, watak atau karakter lain yang perlu dikembangkan adalah karakter "produktif" dan "kreatif/inovatif"' dalam berfikir dan berkarya (Megawangi, 2004).

Pada prinsipnya, suatu praktek pendidikan karakter haruslah bersandar pada nilai-nilai yang dianggap sebagai sesuatu yang istimewa, baik, luhur bagi komunitas masyarakat tersebut. Setelah itu, nilai-nilai tersebut dipergunakan sebagai acuan perilaku dalam kehidupan sehari-hari.

Apapun pilihan nilai yang ditentukan dan menjadi acuan dalam pengembangan karakter peserta didik, yang paling penting dilakukan adalah mencanangkan pelaksanaan strategi pendidikan yang tepat agar karakter luhur itu dapat berkembang dan terinternalisasi efektif dalam diri setiap peserta didik melalui pengembangan pendidikan karakter di sekolah. Peran sekolah dalam ikut membangun watak peserta didik tetaplah lebih penting, sebagaimana dikatakan Lickona (1993): "School must help 
children understand core values, adopt or commit to them, and then act upon them in their own lives".

Beragam cara kreatif dapat dicoba dilakukan dalam pendidikan karakter di sekolah. Namun perlu diperhatikan bahwa pengembangan karakter luhur hanya akan tumbuh sehat, bila ada dukungan kuat dari komunitas tempat seseorang hidup seharihari. Komunitas yang sehat adalah komunitas yang di dalamnya terjadi interaksi yang sejajar, yakni masing-masing anggota memiliki kesamaan derajat, ada kesamaan tingkat keterlibatan, dan ada sikap keterbukaan. Langkah membangun interaksi sehat ini memerlukan pemahaman dan latihan terus-menerus. Manakala komunitas semacam ini terbangun, maka setiap anggota di dalamnya memiliki jalinan hubungan erat yang diikat oleh nilai-nilai moral yang disepakati bersama.

Karakter sebaiknya diajarkan secara sistematis dalam proses pendidikan yang holistik menggunakan metode "knowing the good, feeling knowing the good, and acting the good. Setelah peserta didik memiliki pengetahuan baru ditumbuhkan feeling loving the good, yakni bagaimana merasakan dan mencintai kebajikan, sehingga senantiasa mau berbuat sesuatu kebaikan (acting the good), yang pada akhirnya tumbuh kesadaran dan kebiasaan untuk selalu berbuat baik. Salah satu strategi atau cara untuk mewujudkan hal tersebut adalah dengan memasukkan pendidikan karakter dalam semua mata pelajaran di sekolah (Suyanto, 2009)

Tthe belief that character education implementation in schools is related to academic achievement of studen ts in those schools has great intrinsic appeal (Benninga, 2003). Termed character education in today's world has been called many things throughout the history of education in this country. Character education has been both a formal and informal part of schools. At times it has been integrated in small ways into many other pieces of the curriculum (Watz, 2011).

Pendidikan karakter atau proses pembentukan karakter harus dilakukan secara sistematis dan berkesinambungan yang melibatkan aspek "knowledge, feeling, loving and action". Pembentukan karakter dapat dibaratkan seperti proses "body builder" yang memerlukan latihan dan pembiasaan secara terus menerus agar bisa menjadi kokoh dan kuat (Lickona, 1991). Good character is not formed automatically, it is developed over time through a sustained process of teaching, example, learning and practice. It is developed through character education. Quality of character education helps schools create a safe, caring and inclusive learning environment for every student and supports academic development. It fosters qualities that will help students be successful as citizens, in the workplace, and with the academic curriculum (Lickona, 2002).

Hal tersebut ternyata selaras dengan temuan penelitian yang menunjukkan bahwa kelestarian nilai-nilai luhur pada masyarakat Samin, merupakan hasil dari pendidikan karakter di lingkungan masyarakatnya.

Pernyataan di atas telah dipraktekkan dalam kehidupan sehari-hari masyarakat Samin. Masyaramat Samin secara filosofis, para sesepuhnya telah mengembangkan nilai-nilai luhur yang menjadi dasar kehidupannya, menjabarkan dan mengimplementasikannya serta diaktualisasikan dalam kehidupan sehari-hari.

Centre for Character \& Value University of Birmingham (2012) mengemukakan bahwa.

"The development of character is a process that requires the efforts of both the developing individual and the society and its schools. A society determined to enable its members to live well will treat character education as something to which every child has a right. Questions about the kinds of persons children will become, the contributions of good character to a flourishing life, and how to balance various virtues and values in this process are therefore salient concerns for all schools. 
Oleh karena itu pendidikan karakter perlu diupayakan dan diimplementasikan pada jalur pendidikan formal, informal dan non formal. Berdasarkan grand design yang dikembangkan Kemendiknas (2017), secara psikologis dan sosial kultural pembentukan karakter dalam diri individu merupakan fungsi dari seluruh potensi individu manusia (kognitif, afektif, konatif dan psikomotorik) dalam konteks interaksi sosial kultural (dalam keluarga, sekolah dan masyarakat) dan berlangsung sepanjang hayat. Konfigurasi karakter dalam konteks totalitas proses psikologis dan sosial-kultural dapat dikelompokkan dalam: (1) olah hati (spiritual and emotional development), (2) olah pikir (intelectual development), (3) olah raga dan kinestetik (physical and kinesthetic development), (4) olah rasa dan karsa (affective and creativity development), keempat hal tersebut tidak dapat dipisahkan satu dengan yang lain bahkan saling melengkapi dan saling berkaitan.

Jadi adalah benar, bilamana lembaga pendidikan seperti sekolah mengembangkan pendidikan karakter dengan mengacu kepada nilai-nilai Pancasila sebagai acuan utama dalam implementasi dan atualisasi, serta internalisasinya.

Berdasarkan temuan penelitian serta pembahasan yang telah dilakukan diketahui bahwa mekanisme atau grand design dari pendidikan karakter adalah diawali dengan penentuan nilai-nilai luhur yang diyakini mampu menjadikan kehidupan manusia lebih baik dibanding sebelumnya, nilai-nilai luhur tersebut selanjutnya diaktualisasikan dalam kehidupan sehari-hari manusia dalam komunitas dengan berbagai wujudnya, serta diinternalisasikan kepada generasi mudanya.

\section{SIMPULAN}

Pendidikan karakter tidak bisa dipisahkan dari praktek pendidikan, karena pengembangan karakter manusia yang merupakan kunci dari keberhasilan pendidikan dalam membangun peradaban kehidupan manusia. Nilai-nilai luhur dalam kehidupan manusia merupakan perwujudan dari keyakinan masyarakat akan keunggulan atau keluhuran dari nilai-nilai tersebut dalam meningkatkan kualitas kehidupan dan peradaban manusia. Oleh karena itu suatu komunitas, apapun bentuknya, pasti memiliki nilai-nilai luhur yang diyakini keluhurannya dan dijadikan acuan dalam berperilaku.

\section{DAFTAR PUSTAKA}

Benninga, J.S., ed. 1991. Moral, Character, and Civic Education in the Elementary School. New York: Teachers College Press.

BSNP. 2010. Paradigma Pendidikan Nasional Abad XXI. Badan Standar Nasional Pendidikan. Jakarta. Depdiknas.

Center for Civic Education/CCE. 1994. Civitas: National Standards for Civics and Government. Calabasas: CCE.

Gagne, Robert M and Briggs. 2005. Principles of Instructional Design. Fifth Edition. Florida, USA: Wadsworth Cengage Learning.

Hanafi, Imam. 2010. Saminisme/Ajaran Samin. https://imamhanafo.wordpress.com /2010/06/20/saminisme-ajaran-samin/

Kementerian Pendidikan dan Kebudayaan, 2017. Konsep dan Pedoman PPK. Tim PPK Kemendikbud

Koesoema A, Doni. 2007. Pendidikan Karakter: Strategi Mendidik Anak di Zaman Global. Jakarta. PT. Grasindo.

Lickona, T., Schaps, E., \& Lewis, C. 2002. Eleven Principles of Effective Character Education. Washington DC: Character Education Partnership.

Megawangi, Ratna. 2004. Pendidikan Karakter: Solusi Yang Tepat Untuk Membangun Bangsa.Tanpa Tempat: Indonesia Heritage Foundation.

Muslich, Masnur. 2011. Pendidikan Karakter, Menjawab Tantangan Krisis Multidimensional. Jakarta. Bumi Aksara.

Peraturan Presiden No. 87 tahun 2017 tentang Penguatan Pendidikan karakter. 
Samani, Muchlas., Hariyanto. 2012. Konsep dan Model Pendidikan Karakter. Bandung. Remadja Rosdakarya.

Suyanto. 2009. Urgensi Pendidikan Karakter.

http://www.mandikdasmen.depdiknas.go.id /web/pages/urgensi.html.

Undang-undang No. 20 tahun 2003 tentang Sistem Pendidikan Nasional.

Watz, Michael. 2011. An Historical Analysis of Character Education. Journal of Inquiry \& Action in Education, 4(2), 2011.

https://www.birmingham.ac.uk/schools/education/jubilee-centre/index.aspx 